\title{
Study Experimental Joining Dissimilar Metal of Cemented Carbide and Carbon Steel under TIG Brazing
}

\author{
Fadelan, Yoyok Winardi, Wawan Trisnadi Putra \\ Faculty of Engineering, Universitas Muhammadiyah Ponorogo, Indonesia
}

Received: July 7, 2021. Revised: November 28, 2021. Accepted: December 28, 2021. Published: December 29, 2021.

\begin{abstract}
In the manufacturing industry, cutting tools are the main component. To produce the best performance of the cutting tool is required high cost. The cemented carbide and steels are joined using brazing. The aim of the work is to investigate the joining of dissimilar metals between cemented carbide and carbon steel using arc brazing. The TIG brazing method has been prepared for the joining of carbide insert and carbon steel. Phenomena that occur in the joint were observed using a scanning electron microscope (SEM). The composition of the constituent elements of the brazed area was characterized by energy dispersive spectroscopy (EDS). Vickers hardness machine is used to hardness test in the brazed area. The results of the microstructure analysis and EDS test composition indicate that solid solution phase enriched $\mathrm{Cu}$ is detected in the brazed area. The $\mathrm{Fe}$ and $\mathrm{C}$ elements are diffusions into the brazed area. The hardness value in the brazed area is $12,16 \mathrm{HVN}$, greater than based metals especially SS400. Thus, the solid solution phase of $\mathrm{Cu}$ and elements of $\mathrm{Fe}$ and $\mathrm{C}$ affect the hardness value.
\end{abstract}

Keywords-Dissilmilar joint, Cemented carbide, Carbon steel, CuSi alloy

\section{INTRODUCTION}

$\mathrm{C}$ EMENTED carbide is one of the hard materials, wearresistant, and high temperature resistant. The advantages of cemented carbides are used to make cutting tools. However, cemented carbide is more expensive, because the main composition is tungsten and cobalt. To reduce the cost production of cutting tools, cemented carbide is joined with steel. However, the joining cemented carbide to steel sis so difficult by confensional fusion welding, because the two materials are of different types. The main reason is due to the difference in thermal expansion between the two materials [1][5].
Technologies are developed to joint the dissimilar metals, such as diffusion bonding[6], TIG brazing [7], electron beam welding [8], etc. Brazing is one of the special techniques for joining dissimilar metals, because the base metal is not melted, and has low residual stress. The brazing process is affected by heat input, filler metal, and characteristics of base metal. In recent years, joining dissimilar metal have been studied. Winardi (2018) [9] is researching the effect of post-brazed heat treatment on the microstructure and shear strength of cemented carbide and carbon steel using Ag-based alloy. The torch brazing is used in the joining process, and the heat treatment process is done in the induction furnace. The result of the examination shows, the increasing temperature of heat treatment leads to an increase in solid solution phase enrich $\mathrm{Cu}$. The maximum shear test is $214.14 \mathrm{MPa}$ at $750^{\circ} \mathrm{C}$. Jing et al ( 2014) [10] also investigated the joining of Titanium alloys with steel using $\mathrm{CuNi}$ as filler metal. It was stated that at low temperatures, the filler metal is difficult to formed to the based metal. The higher the brazing temperature, the layer and solid solution of the filler metal increases which can increase the shear strength of the brazed joint, On the other hand, if a layer and a less solid solution are formed on the surface of the base metal, the mechanical strength decreases. Maximum strength reaches $260 \mathrm{MPa}$ when brazed at $910^{\circ} \mathrm{C}$. Jiang et al (2016) [11] investigated the joining of WC-CO and steel using Ag-Cu filler metal. from the results of testing and observation, it was found that, solid solution of $\mathrm{Cu}$ is widely dispersed in the filler metal and has an important function to increase the strength of the joint because it has high hardness. The joint strength increases with the widening of the -Cu layer. With increasing 
brazing temperature and holding time, the total area and amount of $-\mathrm{Cu}$ decreased. The results of the mechanical test showed that the maximum shear strength of the joint was 366 $\mathrm{MPa}$ when brazed at a temperature of $770^{\circ} \mathrm{C}$ for 30 minutes.

$\mathrm{Cu}-\mathrm{Si}$ is one of the $\mathrm{Cu}$ alloys widely used to filler metal [12]-[14]. The lower melting temperature of CuSi makes it ideal for joining $\mathrm{Cu}$ to steel, galvanized steel, and others. This advantage is very interesting to be developed in the joining of dissimilar metals. In addition, the $\mathrm{CuSi}$ is also suitable to TIG process. So, the main contribution of this study is investigate the dissimilar metal joint between cemented carbide and carbon steel using $\mathrm{CuSi}$ alloy under TIG brazing. The phenomena occurring around the joint will be investigated and discussed.

\section{EXPERIMENTAL}

The base materials with different properties are made as to the specimen, namely, YG6 cemented carbide \& SS400 carbon steel. In the experimental, filler metal using $\mathrm{CuSi}$ alloy. The chemical compositions of the base material and filler metals are listed in Table 1. Before brazing, the surface of carbon steel is clean with Sic paper. The arrangement of the joint is shown in Figure 1. The surface gap of the specimen is measured using a thickness gauge $(0.1 \mathrm{~mm})$. The jointing operation is done using the TIG process at $80 \mathrm{~A}$. Ar at a $5 \mathrm{~L} / \mathrm{m}$ flow rate is used as the shielding gas. After the brazing process, the specimen is cut into $10 \times 10 \times 5 \mathrm{~mm}$. The surface of the brazed area is polished using $\mathrm{SiC}$ paper grid 400 to 2500 and then polished using metal polish paste. The microstructure specimen is analyzed using a Scanning electron microscope (SEM). The element of the microstructure is known by energy dispersive spectroscopy (EDS). The hardness value is tested using a Vickers hardness machine.

Table 1. Chemical compositions of base materials and filler alloy.

\begin{tabular}{ccccccccccc}
\hline Element & W & C & CO & Fe & Cu & Si & Ti & Mn & P & S \\
\hline YG6 & 83.30 & 10.29 & 2.43 & 1,45 & - & - & 2.54 & - & - & - \\
SS400 & - & 0.11 & - & main & - & 0.22 & - & 0.59 & 0.017 & 0.02 \\
Filler & - & - & - & - & 97 & 3 & - & - & - & - \\
Alloy & & & & & & & & & & \\
\hline
\end{tabular}

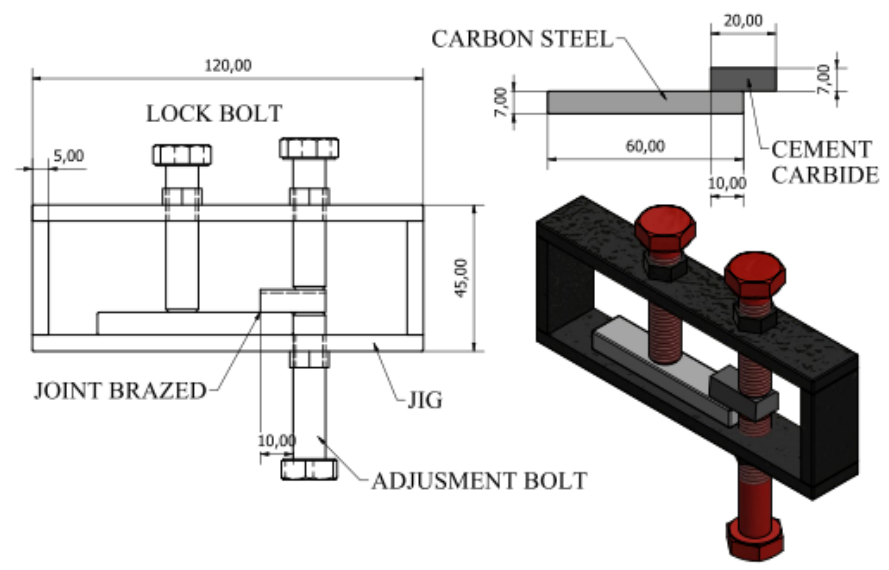

Fig. 1 The arrangement of the brazed joint

\section{RESULT AND DISSCUSIONS}

After being brazed using $\mathrm{CuSi}$ alloy, the specimen surface was cut and smoothed using sandpaper. The cross-section of the brazed joint dissimilar metal between cemented carbide and carbon steel is shown in Figure 2. During the brazing process, $\mathrm{Cu}$ deposition has been successfully achieved. There are no visible defects in the cross-section. During the brazing process, the penetration that occurs into the surface of the base metal (SS400) is very deep due to the influence of the brazing current. The arc generated by the brazing current causes little damage to the base metal. The location of the damage is shown in the red mark in Figure 2. The high heat input causes the steel surface to melt and mix with the filler metal. The phenomenon is the same as that experienced by Lee (2019)[15]. Two types of damaged parts can be seen (Figure $3)$ : the upper and lower sides of the base metal, which are affected directly and indirectly by the arc. Usually, penetration occurs on the underside of the lap joint due to the presence of the HAZ with the arc pool. 


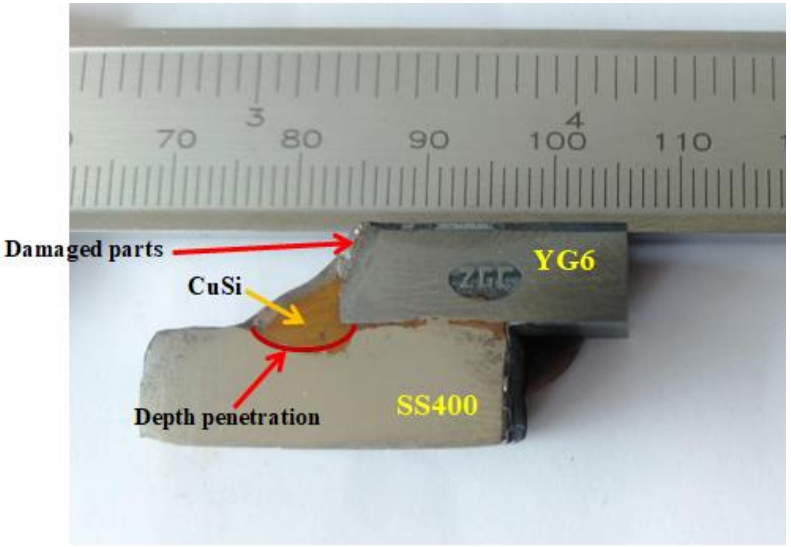

Fig. 2 Cross section of brazed joints using $\mathrm{CuCi}$

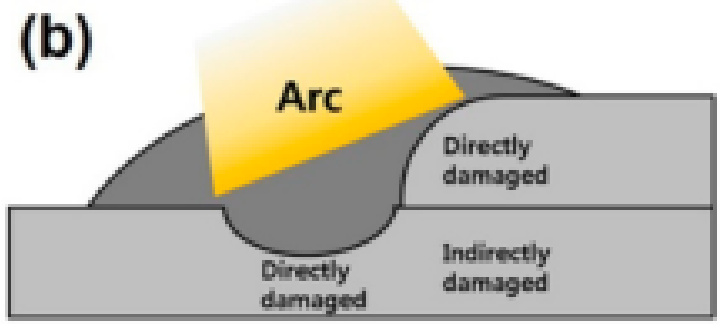

Fig. 3 locations of damaged parts (Lee et al 2019)

To investigate the properties of the brazing layer, we analyzed the microstructure of the brazed joint. Figure 2 shows the microstructure of the dissimilatr metal between cemented carbide and carbon steel brazed using a $\mathrm{CuSi}$ alloy. Microstructure clearly visible that the interface is free from defects, such as pores, cracks, incomplete solidification, inclusions, and others. This indicates that the filler metal has good wettability on the base metal

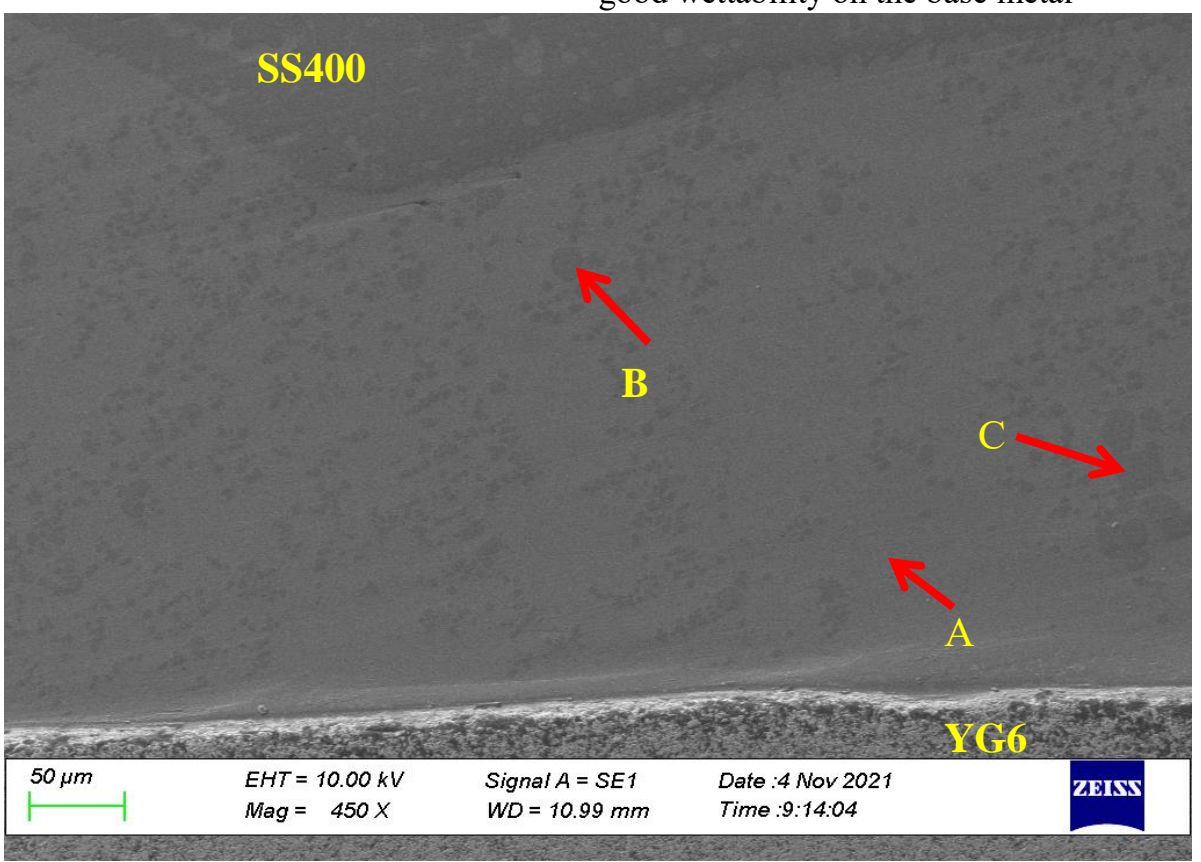

Fig. 3 Microstructure of TIG brazed joints with $\mathrm{CuSi}$

reaching $2.90 \%$, and the smallest being $\mathrm{Si}$ at $1.46 \%$, respectively.

Table 2. EDS results at each point in Figure 2 (wt\%)

\begin{tabular}{ccccccc}
\hline & W & CO & C & Fe & Cu & Si \\
\hline A & - & - & 4.32 & - & 94.92 & 0.76 \\
B & - & - & & 62.95 & 33.86 & 3.19 \\
C & - & - & 2.90 & 44.41 & 51.23 & 1.46 \\
\hline
\end{tabular}

Based on the EDS results in Table 2, it can be seen that the Fe element is able to diffuse into the filler metal area. In addition to $\mathrm{Fe}$ elements, there are also $\mathrm{C}$ elements released from the base metal (SS400). Due to the high brazing current, the heat input to the base metal is also greater. This causes some of the base metal surface to melt and mix with filler metal deposits. In addition to the influence of heat input, the degradation of the base metal is also caused by the low brazing speed The 
brazing speed varies inversely with the heat input. Heat input is very large at lower brazing speeds, and excess heat causes deep penetration [16]-[18]. The thermal diffusivity of the base metal is the most important for the penetration sensitivity due to the cooling rate. Lee (2019) [12] stated that proper arc current and velocity are required even if the brazing temperature is more than the melting temperature of the base metal. The smelting of the base metal and filler creates a fusion zone, having a depth and width of penetration.

The mechanism for the formation of the microstructure above cannot be separated from the action and interaction of heat synthesized by the arc and the interaction between $\mathrm{Cu}, \mathrm{Fe}$, and Si. During the TIG brazing process, the brazing arc current causes high heat to be transferred continuously and hits the steel surface, causing the steel surface to melt. Then some of the Fe element is extruded out and settles around the location of the area affected by the arc current, as shown in Figure 3. On the other hand, some of the Fe elements mix with the liquid metal $\mathrm{Cu}-\mathrm{Si}$ to form a solid solution of $\mathrm{CuFeSi}$. In this case, the element Fe detected is very small.

To clarify the results of the analysis, element mapping using EDS is shown in Figure 4. The green color is the result of mapping the $\mathrm{Cu}$ element, the red color is the map of the $\mathrm{Fe}$ element, the purple color is the image of the distribution of the $\mathrm{Si}$ element, and the light blue color is the capture of the $\mathrm{W}$ element. Based on Figure 4, the braze area is dominated by $\mathrm{Cu}, \mathrm{Fe}$, and a small part of $\mathrm{Si}$.

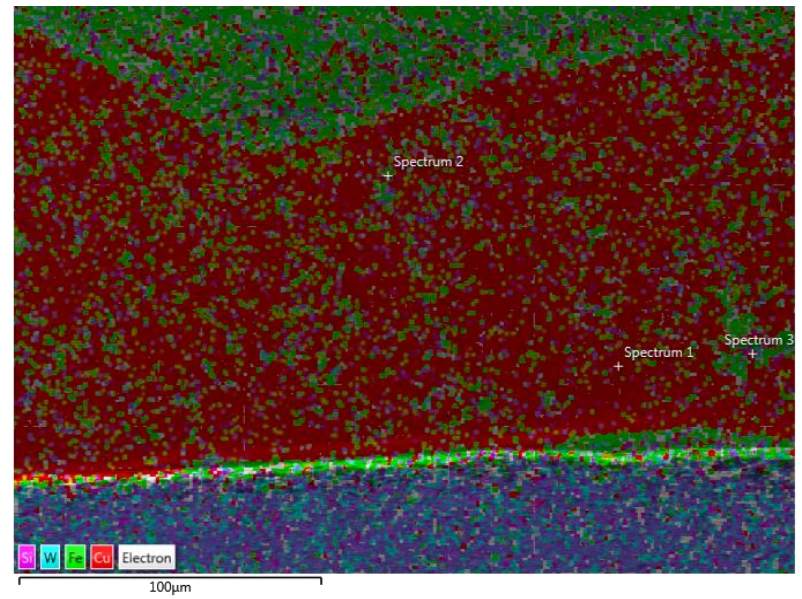

Fig. 4 EDS mapping element

The results of the EDS mapping show that there are 2 phases in the braze area, namely the $\mathrm{Cu}$ matrix and the Fe solid solution. It can be seen that the Fe element is able to diffuse and spread widely into the filler metal area. Fe elements are evenly distributed throughout the layer.

It can be concluded that these particles result from the action of the anode arc welding. Because the welding machine is operated in DCSP mode, a high-density electric current flow from the cathode to the anode. During the arc brazing process, many high bright spots are observed on the surface of the base material, and these points are the anode points. The 'anode point' action causes the micro-iron particles to melt and migrate, and are distributed throughout the filler metal zone [19]. To determine the phase formation, the Fe-Si binary phase diagram is studied, there are several possibilities for the formation of compounds such as FeSi, FeSi2, Fe5Si3, Fe2Si, and others [20]. The Fe-Si compounds will not be produced and grow at the same time. It is important to determine the Gibbs free energy and the diffusion coefficient of each compound using thermodynamic calculations [21]-[22]. However, in the mapping in Figure 4 no compounds were detected because the particles do not have enough energy to form compounds

\section{HARDNESS}

The distribution of hardness values at the joints was detected using Vickers Hardness measured from one end to the other with a load of $30 \mathrm{gf}$ for 30 seconds. The hardness value in the connection area is $12.16 \mathrm{HV}$. In base metals, especially carbon steels close to the brazed area, the hardness value is smaller than the brazed area, which is $10.15 \mathrm{HV}$, and in cemented carbide $70.21 \mathrm{HV}$. The diffusion of $\mathrm{Fe}$ and $\mathrm{C}$ elements in the brazed area has a significant impact on the brazed area. The hardness value of the brazed area is higher than that of the base metal, especially carbon steel.

\section{CONCLUSION}

This study was carried out to investigate the microstructure and mechanical properties dissimilar metal cemented carbide and carbon steel using $\mathrm{CuSi}$ alloy under TIG brazing. The result obtained are summarized as follow:

1. The brazed layer consist matrix of $\mathrm{Cu}$, and solid solutions enriched $\mathrm{Fe}$ and $\mathrm{Cu}$. The $\mathrm{Fe}$ and $\mathrm{C}$ element dissolution from based metal especially carbon steel (SS400).

2. The diffusions of $\mathrm{Fe}$ and $\mathrm{C}$ element in the brazed area are contributed to hardness. The hardness value in the barazed area is greater than based metal.

For future work, the study is focused to investigate the intermetallic compounds in the brazing area.

\section{References}

[1] Y. Guo, B. Gao, G. Liu, T. Zhou, G. Qiao. Effect of temperature on the microstructure and bonding strength of partial transient liquid phase bonded $\mathrm{WC}-\mathrm{Co} / 40 \mathrm{Cr}$ joints using $\mathrm{Ti} / \mathrm{Ni} / \mathrm{Ti}$ interlayers, Int. J. Refract. Met. Hard Mater, 2015, Vol. 51, pp. 250-257.

[2] K. Kaiwa, S. Yaoita, T. Sasaki, T. Watanabe. Effects of $\mathrm{Ni}$ and Co Additions to Filler Metals on Ag-Brazed Joints of Cemented Carbide and Martensitic Stainless Steel, Adv. Mater. Res., 2014, Vol. 922, pp. 322-327.

[3] M. Amelzadeh, S. E. Mirsalehi. Influence of braze type on microstructure and mechanical behavior of $\mathrm{WC}-\mathrm{Co} / \mathrm{steel}$ dissimilar joints, J. Manuf. Process., 2018, Vol. 36, pp. 450-458. 
[4] M. Amelzadeh, S. E. Mirsalehi. Dissimilar joining of WCCo to steel by low-temperature brazing. Materials Science and Engineering: B, 2020, Vol. 259, pp. 114597.

[5] H. Chen, K. Feng, S. Wei, J. Xiong, Z. Guo, and H. Wang. Microstructure and properties of $\mathrm{WC}-\mathrm{Co} / 3 \mathrm{Cr} 13$ joints brazed using $\mathrm{Ni}$ electroplated interlayer, Int. J. Refract. Met. Hard Mater, 2012. Vol. 33, pp. 70-74.

[6] A. Amirnasiri, N. Parvin. Dissimilar diffusion brazing of WC-Co to AISI 4145 steel using RBCuZn-D interlayer. Journal of Manufacturing Processes, 2017, Vol 28, pp. 82-93.

[7] B. Cheniti, D. Miroud, R. Badji, D. Allou, T. Csanádi, M. Fides, P. Hvizdoš. Effect of brazing current on microstructure and mechanical behavior of WC-Co/AISI 1020 steel TIG brazed joint. International Journal of Refractory Metals and Hard Materials, 2017, Vol. 64, pp. 210-218.

[8] G. Chen, X. Shu, J. Liu, B. Zhang, B. Zhang, J. Feng, Investigation on microstructure of electron beam welded WC-Co/40Cr joints, Vacuum, 2018, Vol. 149, pp. 96100.

[9] Y. Winardi, Triyono, N. Muhayat. Effect of Post-Braze Heat Treatment on the Microstructure and Shear Strength of Cemented Carbide and Steel Using Ag-Based Alloy. In IOP Conference Series: Materials Science and Engineering, 2018, Vol. 333, No. 1, art. id. 012039.

[10] Y. Jing, Q. Yang, W. Xiong, B. Huang, B. Li, M. Zhang. Microstructure and shear strength of brazed joints between $\mathrm{Ti}(\mathrm{C}, \mathrm{N})$-based cermet and steel with $\mathrm{CuAgTi}$ filler metal, J. Alloys Compd., 2016, Vol. 682, pp. 525530.

[11]C. Jiang, H. Chen, Q. Wang, Y. Li, Effect of brazing temperature and holding time on joint properties of induction brazed WC-Co/carbon steel using Ag-based alloy, J. Mater. Process. Technol., 2016, Vol. 229, pp. $562-569$.

[12] K. Nagatsuka, Y. Sechi, N. Ma, K. Nakata. Simulation of cracking phenomena during laser brazing of ceramics and cemented carbide. Science and Technology of Welding and Joining, 2014, Vol. 19, No. 8, pp. 682-688.

[13] S. Li, Z. Li, Y. Chen, Y. Zu, J. Xiong, F. Zhang, J. Li. Microstructural evolution and mechanical properties of diffusion bonding WC-Co cemented carbide to steel using $\mathrm{Co}$ and composite $\mathrm{Ni} / \mathrm{Co}$ interlayers. International Journal of Refractory Metals and Hard Materials, 2022, Vol. 103, art. id. 105736.

[14] C. M. Fernandes, A. M. R. Senos. Cemented carbide phase diagrams: a review. International Journal of Refractory Metals and Hard Materials, 2011, Vol. 29, No. 4, pp. 405-418.

[15] S. J. Lee, A. Sharma, D. H. Jung, J. P. Jung. Influence of arc brazing parameters on microstructure and joint properties of electro-galvanized steel, Metals (Basel)., 2019, Vol. 9, No. 9, art. id. 1006.

[16]B. Ma, X. Wang, C. Chen, D. Zhou, P. Xu, X. Zhao. Dissimilar welding and joining of cemented carbides. Metals, 2019, Vol. 9, No. 11, art. id. 1161.
[17]C. Barbatti, J. Garcia, G. Liedl, A. Pyzalla. Joining of cemented carbides to steel by laser beam welding. Materialwissenschaft und Werkstofftechnik: Entwicklung, Fertigung, Prüfung, Eigenschaften und Anwendungen technischer Werkstoffe, 2007, Vol. 38, No. 11, pp. 907-914.

[18] J. Garcia, V. C. Cipres, A. Blomqvist, B. Kaplan. Cemented carbide microstructures: a review. International Journal of Refractory Metals and Hard Materials, 2019, Vol. 80, pp. 40-68.

[19]Z. S. Yu, R. F. Li, and K. Qi. Growth behavior of interfacial compounds in galvanized steel joints with $\mathrm{CuSi} 3$ filler under arc brazing. Trans. Nonferrous Met. Soc. China (English Ed). 2006. vol. 16, no. 6, pp. 13911396.

[20] A. Sharma, S. J. Lee, D. Y. Choi, and J. P. Jung. Effect of brazing current and speed on the bead characteristics, microstructure, and mechanical properties of the arc brazed galvanized steel sheets. J. Mater. Process. Technol.2017. Vol. 249, pp. 212-220.

[21]F. Alexe, V. Cenusa. Thermodynamic Analyses for Optimizing the Design of HTGR's Helium Brayton Cycles. WSEAS Transactions on Environment and Development, 2008, Vol. 11, No. 4, pp. 1014-1025.

[22] M. A. Alghoul, M. Y. Sulaiman, K. Sopian, M. Yahya, A. Zaharim. Experimental and simulation study on malaysian activated carbon as adsorbent in a dual-purpose solar system. WSEAS Transactions on environment and development, 2009, Vol. 5, No. 3, pp. 331-339.

\section{Sources of Funding for Research Presented in a Scientific Article or Scientific Article Itself}

This work was supported by a PTUPT 2021 research grant from the Ministry of Education, Culture, Research, and Technology of the Republic of Indonesia [contract \# 13/E4.1/AK.04.PT/2021;18/AMD-SP2H/LT-MULTITERAPAN/LL7/2021; 140/VI.4/PN/2021]

\section{Creative Commons Attribution License $\mathbf{4 . 0}$ (Attribution 4.0 International, CC BY 4.0)}

This article is published under the terms of the Creative Commons Attribution License 4.0

https://creativecommons.org/licenses/by/4.0/deed.en_US 